\title{
Interactions between Host PPARs and Gut Microbiota in Health and Disease
}

\author{
Arif Ul Hasan $\mathbb{D}^{\mathbb{D}}$, Asadur Rahman $\mathbb{D}^{\mathbb{D}}$ and Hiroyuki Kobori * $\mathbb{E}$ \\ Department of Pharmacology, School of Medicine, International University of Health and Welfare, 4-2 \\ Kozunomori, Narita, Chiba 286-8686, Japan; hasan@iuhw.ac.jp (A.U.H.); rahmanma@iuhw.ac.jp (A.R.) \\ * Correspondence: hkobori@iuhw.ac.jp; Tel.: +81-(0)-476-20-7701; Fax: +81-(0)-476-20-7702
}

Received: 26 October 2018; Accepted: 5 January 2019; Published: 17 January 2019

\begin{abstract}
The human gastrointestinal tract is inhabited by many types of microbiota, including bacteria, viruses, and fungi. Dysregulations of their microenvironment are associated with various health problems, not only limited to gastrointestinal disorders, such as inflammatory bowel disease, but to impacts beyond the intestine. For example, intestinal microbiota can affect the liver in non-alcoholic fatty liver disease, visceral adipose tissue during adipogenesis, and the heart in atherosclerosis. The factors contributing to these pathogeneses involve the gut microbiota and the effector organs of the host, and everything in between. The nuclear receptor peroxisome proliferator-activated receptors (PPARs) are pivotal for the modulation of many of the pathogeneses mentioned above. It is, therefore, conceivable that, in the process of host-microbiota interactions, PPARs play important roles. In this review, we focus on the interactions between host PPARs in different organs and gut microbiota and their impacts on maintaining health and various diseases.
\end{abstract}

Keywords: atherosclerosis; inflammatory bowel disease; irritable bowel syndrome; metabolic syndrome; non-alcoholic liver diseases; obesity; type 2 diabetes mellitus

\section{Introduction}

Each of us hosts trillions of lives along with us, remaining unnoticed most of the time. These lives are the bacteria, archaea, and viruses residing on the surface of our body and inside the gut [1]. The gut-dwelling microbes are influenced by the part of the globe in which we live, the type of foods we eat, our age, how we were born, and many more factors [1-3]. The skin microbial community is influenced by external factors such as climate and hygiene, as well as internal factors, such as physiology and disease state [1]. As a result, the microbial community we host, both inside and out, is exclusive to each individual [3].

Are these bacteria our friends or foes? Do these host-specific diversities in the bacterial population have any impact on our health? Answers to these questions reside inside us. Any of the gut- or skin-dwelling microbial populations have potential impacts on our health. However, for the purposes of this review, we confine our discussion to the bacterial communities in the human intestine. The intestinal microbes reside in our hostile but nutrition-rich gastrointestinal tract at the cost of helping us digest complex forms of foods. All these microbes inhabiting within us together encode over three million genes, which is 150 times of the number of human genes [4]. Utilizing these genes, the microbes produce short-chain fatty acids (i.e., butyrate, propionate, etc.) [5], ligands for G-protein-coupled receptors (i.e., $\mathrm{N}$-acyl amide) [6], neurotransmitters (i.e., serotonin, dopamine, etc.) [7], and other metabolites. These metabolites genetically and epigenetically influence host responses [2].

Despite these beneficial effects, we are always at risk of infection [8]. Therefore, our gut epithelium tries to protect us by not allowing these microbes and their harmful products to enter our system. Scientists provided compelling evidence of the relationship between some diseases and disequilibrium 
in the microbiota. These diseases include type 2 diabetes mellitus, non-alcoholic fatty liver diseases, irritable bowel syndrome, and inflammatory bowel diseases [9]. Most of these incurable diseases are a socio-economic burden for many countries.

From the historical perspective of gut-centered disease, possibly pioneered by the view of the "father of modern medicine", Hippocrates, "all disease begins in the gut". Indeed, fecal microbiota transplantation was successfully used to treat inflammatory bowel diseases and irritable bowel syndrome, and is thought to have roles in type 2 diabetes and metabolic diseases [10,11]. Details of the beneficial or adverse effects of these host-microbiota interactions were reviewed elsewhere. However, in this vast field, some interesting interactions occur between a group of transcriptional factors, called peroxisome proliferator-activated receptors (PPARs), with gut microbiota, which we review here.

In humans, the nuclear receptor superfamily includes 48 transcriptional factors. They are activated by their specific ligands, and regulate diverse developmental, inflammatory, and metabolic processes $[12,13]$. PPARs are members of this nuclear receptor superfamily. PPARs are composed of three members: PPAR $\alpha, \operatorname{PPAR} \beta / \delta$, and PPAR $\gamma$, also known as nuclear receptor subfamily 1 , group $C$, members (NR1C)-1, -2 , and -3 , respectively. PPAR $\alpha$ was the first member identified in the early 1990s, as a target of hypolipidemic fibrate [14]. Based on their sequence homology, PPAR $\beta / \delta$ and PPAR $\gamma$ were cloned $[15,16]$. Due to their close association with obesity and additional cardiovascular complications, these receptors were extensively studied since their identification $[17,18]$.

PPAR $\alpha$ is predominantly expressed in the liver, as well as in the heart, muscle tissue, kidney, and brown adipose tissue $[17,19]$. PPAR $\alpha$ is mostly involved in $\beta$-oxidation and fatty-acid transportation and, thus, controls lipid homeostasis [20]. PPAR $\beta / \delta$ is expressed in skeletal muscle, the gastrointestinal tract, heart, brown adipose tissue, and white adipose tissue. The high activity of PPAR $\beta / \delta$ in skeletal muscle regulates fatty-acid catabolism. In adipose tissue, it improves lipid metabolism. PPAR $\gamma$ is expressed in brown adipose tissue, white adipose tissue, the colon, and immune cells. In brown adipose tissue, it causes browning of adipocytes and improves thermogenesis. Several major functions of PPAR $\gamma$ include uptake and safe deposition of lipids in adipose tissue, liver, and muscle; regulation of adipocytokine secretion; and improving insulin resistance $[17,20]$.

Given their widespread distribution in various organs, the effects of PPARs are not limited to the abovementioned conditions. Despite the spatial barrier between the PPARs of some organs, such as the liver, adipose tissue, and the intestinal microbiota, they interact with each other. Briefly, the metabolites produced by the microbiota are absorbed by the intestinal epithelial and resident inflammatory cells. The metabolites are also transported to liver, adipose tissue, heart, blood vessels, and other organs through systemic circulation. In these organs, the metabolites act as ligands of PPARs. Activation of PPARs modulate (1) intestinal, as well as the whole-body immune response, and (2) carbohydrate and fat metabolism. From these perspectives, we elaborate upon the molecular mechanisms related to PPARs and gut microbiota in health and some diseases.

\section{Gut Microbiota Composition}

In healthy humans, the number of bacteria in the intestine was previously considered to be around $1 \times 10^{14}$ [21]. According to a recent estimation, the number is thought to be around $3.8 \times 10^{13}$ [22]. As the amount of bacteria is more than 1000-fold lower in the small intestine, the counts of intestinal bacteria mentioned above mostly represent bacteria in the large intestine [22]. The sequencing studies targeting 16s rRNA (small subunit ribosomal RNA) showed that most of these intestinal bacteria fall under four phyla: Firmicutes, Bacteroidetes, Actinobacteria, and Proteobacteria [23]. Each phylum contains many different species [3], resulting in between 1000 and 1150 prevalent bacterial species [4]. However, only about 160 of these species are shared among human subjects [4].

The two predominant phyla are Firmicutes, which includes Lactobacillus, Clostridium, Enterococcus, and Ruminococcus, and Bacteroidetes, which includes Prevotella and Bacteroides genera. In children of Burkina Faso, a West African country, the proportions of Firmicutes and Bacteroidetes were 12\% and $73 \%$, respectively, whereas these proportions in children from Florence, Italy were $51 \%$ and $27 \%$, 
respectively [24]. Differences in dietary habit are considered to shape the bacterial populations in the children from these two geographical areas. Similarly, exclusively formula-fed infants are more colonized with Escherichia coli, Clostridium difficile, Bacteroides fragilis, and Lactobacilli than exclusively breastfed infants [25]. In vaginally delivered infants, Clostridium (C. difficile) and Lactobacillus genera are more common compared with infants delivered via caesarean section [25]. The abundance and diversity of the phyla Actinobacteria and Bacteroidetes are lower in caesarean-section-delivered infants. However, the diversities at 6 to 12 months are similar irrespective of delivery mode [26]. The diversity again appears in patients with various diseases such as type 2 diabetes mellitus, metabolic syndrome, etc. [9]. These observations suggest the existence of host-specific diversities among the bacteria, those that can affect or be affected by the host.

\section{PPARs on Microbial Inhabitation and Adaptation in the Gut}

For colonization and survival in a specific niche, microbiota modulate the expression of PPARs in intestinal epithelial and immune modulatory cells and alter the host inflammatory responses. Therefore, cross-talk between the commensal microbiota and the host cell signaling molecules must start immediately after birth. Enterococcus faecalis is an early colonizer, transferred from mother to child. E. faecalis, when isolated from newborn babies co-cultured with human colorectal adenocarcinoma cell line (HT-29) or murine epithelial cells, showed enhanced PPAR $\gamma 1$ phosphorylation. This phosphorylation also elevated DNA binding of PPAR $\gamma 1$ and its transcriptional activation of an innate immune system modulator, interleukin (IL)-10 [27]. IL-10 binds with the IL-10 receptor expressed in the macrophages, and polarizes the macrophages to an anti-inflammatory phenotype, namely $\mathrm{C}-\mathrm{X}-3-\mathrm{C}$ motif chemokine receptor (CX3CR ${ }^{\text {hi }}$ [28]. These macrophages harness intestinal immune responses to a level suitable for maintaining gut defense without interfering with gut microbial homeostasis. From the opposite perspective, the pathogenic Salmonella typhimurium downregulates PPAR $\gamma$ expression and initiates a local inflammatory response in the intestine. This inflammatory response is hostile for the commensals; thus, this pathogen enables its own colonization [29]. Thus, PPAR $\gamma$-mediated regulation of inflammatory cytokines allows commensal or pathogenic bacteria to colonize the human gut.

However, a contrasting pattern of PPAR $\gamma$ expression was demonstrated for Streptococcus salivarius. Among the commensal intestinal microbiota, S. salivarius is an early colonizer ubiquitously preset in the small and large intestine, with an ileac predominance [30]. In some human epithelial cell lines (HT-29, Caco-2, and SW-116), supernatants collected from S. salivarius reduce an inflammatory mediator: nuclear transcription factor $\mathrm{KB}(\mathrm{NF}-\mathrm{kB})$ [31]. In this report, expression of PPAR $\gamma$ and two of its target genes (intestinal fatty-acid binding protein and angiopoietin-like protein 4 ) was found to be reduced [31]. Although no direct effect of reduced PPAR $\gamma$ expression on NF- $\mathrm{KB}$ downregulation was demonstrated in this in vitro model, the authors assumed that PPAR $\gamma$-mediated suppression of inflammatory responses facilitates $S$. salivarius colonization of the intestine. In a mouse model, short-chain fatty acids (explained below), which are ligands of PPARs [5], cause expansion and differentiation of regulatory $\mathrm{T}$ lymphocytes (known as $\mathrm{T}_{\text {reg }}$ cells). This process limits pro-inflammatory responses and sustains tolerance of commensals [32].

Some of the obligate microbes have the ability to protect intestinal mucosa. Dextran sodium sulfate is a chemical compound that increases intestinal permeability and causes colitis-like effects [33]. Dextran sodium sulfate-induced colitis mice, treated with Lactobacillus paracasei B21060, causes upregulation of PPAR $\gamma$ and $\beta$-defensin. This upregulation is associated with restoration of intestinal integrity. This study suggests that the microbiota influences intestinal PPAR $\gamma$ in maintaining intestinal mucosal homeostasis (Figure 1) [34].

The obligate gut microbiota ferment complex foods and produce several short-chain fatty acids, namely butyrate, acetate, and propionate. Among them, butyrate is the main carbon source for the intestinal epithelial cells [35]. PPAR $\gamma$ responds to butyrate and drives the energy metabolism of these cells toward $\beta$-oxidation, and suppresses synthesis of inducible nitric oxide synthase (iNOS). Thereby, the oxygen bioavailability in the colon decreases. As a result of this PPAR $\gamma$ signaling, the anaerobic 
milieu in the colon is maintained, which prevents growth of facultative anaerobes [36]. However, the microbes differentially produce metabolites; thus, they differentially modulate host epithelial responses. For example, in an ex vivo model, short-chain fatty-acid-induced conditioned medium collected from Akkermansia muciniphila affected expression of 1005 genes in intestinal organoids, whereas Faecalibacterium prausnitzii affected only 503 genes. Among those, PPAR $\gamma$ expression was reduced by the former, whereas the latter showed no effect [37]. The authors also demonstrated that the physiological concentration of butyrate and propionate, but not acetate, modulated PPAR $\gamma$ and angiopoietin-like protein 4 expressions by the A. muciniphila [37].

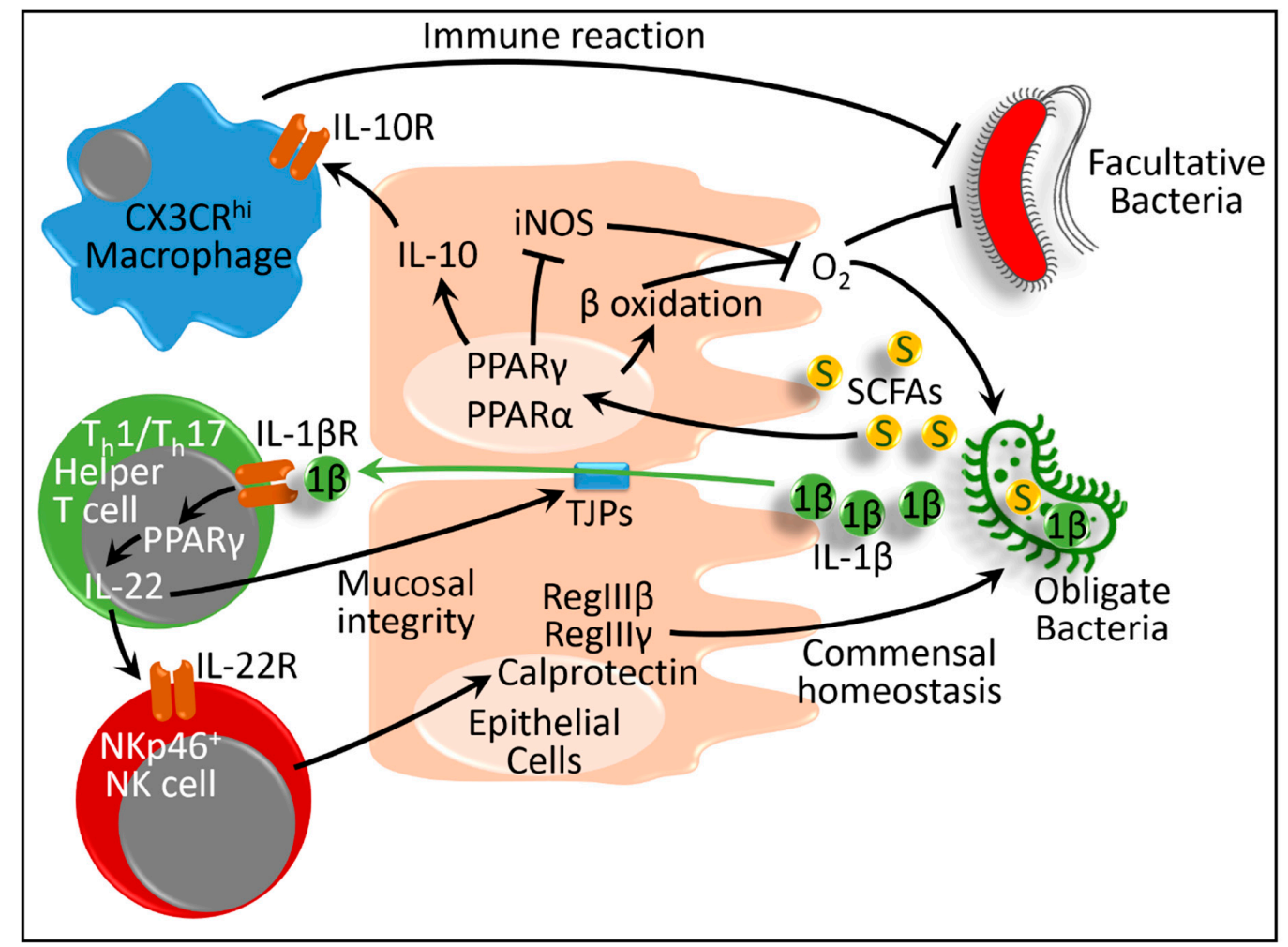

Figure 1. Schematic presentation of interactions between host peroxisome proliferator-activated receptors (PPARs) and gut microbiota in microbial inhabitation and adaptation. IL: interleukin; IL-1 $\beta R$, IL-10R and IL-22R: receptors of interleukin $-1 \beta,-10$ and -22, respectively; iNOS: inducible nitric oxide synthase; PPAR: peroxisome proliferator-activated receptors ( $\alpha$ and $\gamma$ ); S and SCFAs: short-chain fatty acids; TJPs: tight junction proteins. Black lines ending in arrowheads denote activation and lines ending in bars represent inhibition. Green arrow depicts absorption of interleukin $1 \beta$.

In addition to PPAR $\gamma$, PPAR $\alpha$ is important for regulating commensal bacterial homeostasis. Microbiota, in particular the Clostridia-related segmented filamentous bacteria (SFB), produce IL-1 $\beta$, which activates $T$ helper 1 and $17\left(T_{h} 1\right.$ and $\left.T_{h} 17\right)$ cells in the intestine [38,39]. $T_{h} 1$ and $T_{h} 17$ cells are types of cluster of differentiation 4 positive $\left(\mathrm{CD}^{+}\right)$T-helper lymphocytes. They are important for protecting the intestine during enteric infection [39]. $T_{h} 1$ and $T_{h} 17$ lymphocytes express several proinflammatory cytokines such as IL-17A, IL-17F, and IL-22, which are critical for host defense and autoimmunity [40]. For example, IL-22, produced by a type of natural killer (NK) lymphocyte-NKp46 innate cells-regulates intestinal immune responses [41]. This cytokine influences the expression of antimicrobial peptides (RegIII $\beta, \operatorname{RegIII} \gamma$, and calprotectin) via the epithelial cells to maintain the bacterial niche. RegIII $\gamma$ binds to the peptidoglycan surface of Gram-positive bacteria, such as those in the Lactobacillacae family, and confines them within the small intestine but not the colon [42]. IL-22 also maintains epithelial cell barrier integrity and helps in mucous production and epithelial cell regeneration [42,43]. Through these processes, IL-22 restores commensal homeostasis. Therefore, 
the absence of IL-22 increases the susceptibility to pathogenic microbiota [41,42]. In this context, in PPAR $\alpha$ knock-out mice, the absence of PPAR $\alpha$ produced an enhanced inflammatory response even in response to commensal bacteria. As a result, the $T_{h} 1$ and $T_{h} 17$ cells in the intestine increased. However, due to lack of PPAR $\alpha$ overall production of IL-22, RegIII $\beta$ and RegIII $\gamma$ decreased. As a result, dysbiosis occurred [44].

Taken together, although PPAR expression in the intestine or immune cells was not evaluated in all the abovementioned studies, it is conceivable that microbial alteration of PPAR expression, along with its target genes, facilitates intestinal homeostasis for inhabitation and adaptation of the microbes. Considering contradictory findings, the mechanisms mostly involve (1) production of inflammatory cytokines, (2) maintenance of intestinal mucosal homeostasis and integrity, and (3) modulation of immune cells (Figure 1).

\section{Gut Microbiota and PPARs in Diseases}

\subsection{Gut Microbiota and PPAR Interaction in Gastrointestinal Diseases}

Irritable bowel syndrome is characterized by abdominal discomfort or pain and alteration of bowel habits [45]. Among several proposed origins, altered bacterial flora in the pathogenesis of irritable bowel syndrome is quite compelling. Children [46] and adults [47] suffering from irritable bowel syndrome show an increased ratio of Firmicutes to Bacteroidetes. Particularly, two members of Firmicutes, Dorea and Ruminococcus, are abundantly present in these patients. Dorea is capable of producing formic acid [48], and Ruminococcus (Ruminococcus torques) is associated with producing greater pain severity [49]. In irritable bowel syndrome patients who experience alternating constipation and diarrhea (i.e., mixed-type irritable bowel syndrome), expression of PPAR $\gamma$ in colonic mucosa decreases [50]. The studies suggest important associations between dysbiosis of commensal microbes and dysregulation of PPAR $\gamma$ in irritable bowel syndrome [51].

Mice artificially infected with Trichinella spiralis represent an in vivo irritable bowel syndrome model. In this disease model, beneficial Akkermansia decreased and pathogenic bacteria, such as Escherichia/Shigella, increased [51]. In the colonic tissue of these mice, expression of tumor necrosis factor (TNF)- $\alpha$ markedly increased, whereas the levels of PPAR $\gamma$ and a tight junction protein (occludin) decreased. Pretreating these mice with a prebiotic blend (containing fructo-oligosaccharide, galacto-oligosaccharide, inulin, and anthocyanins) ameliorated Trichinella spiralis-induced changes in dysbiosis and dysregulation of TNF- $\alpha$, PPAR $\gamma$, and occludin [51]. Although the underlying mechanism is not well defined, proteomics analysis of this study revealed that the beneficial effects of the prebiotic blend are associated with a PPAR $\gamma$-mediated pathway [51].

Water-avoidance stress in mice is another in vivo model of irritable bowel syndrome. This type of stress reduces the expression of intestinal nucleotide-binding oligomerization domain protein-like receptors, pyrin-domain containing (NLRP)-6 [52]. NLRP6 is an inflammasome that is important for maintaining gut microbial homeostasis. Therefore, water-avoidance stress-induced reduction of NLRP6 causes an increased ratio of the Firmicutes to Bacteroidetes [52], a pattern similar to that seen in irritable bowel syndrome patients [46,47]. Pretreating these mice with probiotic supplementation containing Bifidobacterium bifidum, Lactobacillus acidophilus, and Streptococcus faecalis, or treating with rosiglitazone (a PPAR $\gamma$ agonist) increased NLRP6 and reversed stress-induced intestinal inflammation [52-54].

Similar to irritable bowel syndrome, the etiology of inflammatory bowel diseases is unknown. However, it is assumed that, in genetically susceptible individuals, dietary ingredients either directly [55] or through microbiota [56,57] interact with intestinal immune cells and epithelial cells. These interactions pertain to the inflammatory responses. Supplementation of fructo-oligosaccharide to patients with Crohn's disease, a variant of irritable bowel syndrome, stimulates the growth of beneficial Bifidobacteria. Fructo-oligosaccharides inhibit intracellular transcription factors, such as nuclear factor $\mathrm{KB}$ and, thus, promote IL-10 and inhibit IL-12 expression in intestinal dendritic cells [57]. Peptidoglycan recognition protein 3 (PGlyRP3), a member of the PGlyRP family, acts as a pattern recognition molecule 
in the intestinal epithelium [58]. PGlyRP3 reduces expression of proinflammatory IL-8, IL-12p35, and TNF- $\alpha$ cytokines. PPAR $\gamma$ is a transcriptional activator of PGlyRP3 [59]. As mentioned above, Bifidobacteria produces short-chain fatty acids, such as butyrate, which are ligands for PPARs. Therefore, it is conceivable that oligosaccharide-stimulated Bifidobacteria growth enhances expression of PPAR $\gamma$, and its targets, such as PGlyRP3, reduce proinflammatory cytokines. Additionally, PPAR $\gamma$ supports maintenance of several commensal bacteria such as Candida albicans and Bacteroides fragilis. In this process, PPAR $\gamma$ activates $\beta$-defensin-1-mediated immunity in Crohn's disease [60], which constitutes another intestinal anti-inflammatory mechanism. Presumably, all the above mentioned PPAR-mediated mechanisms are protective against irritable bowel syndrome (Figure 2) $[54,55,61]$.

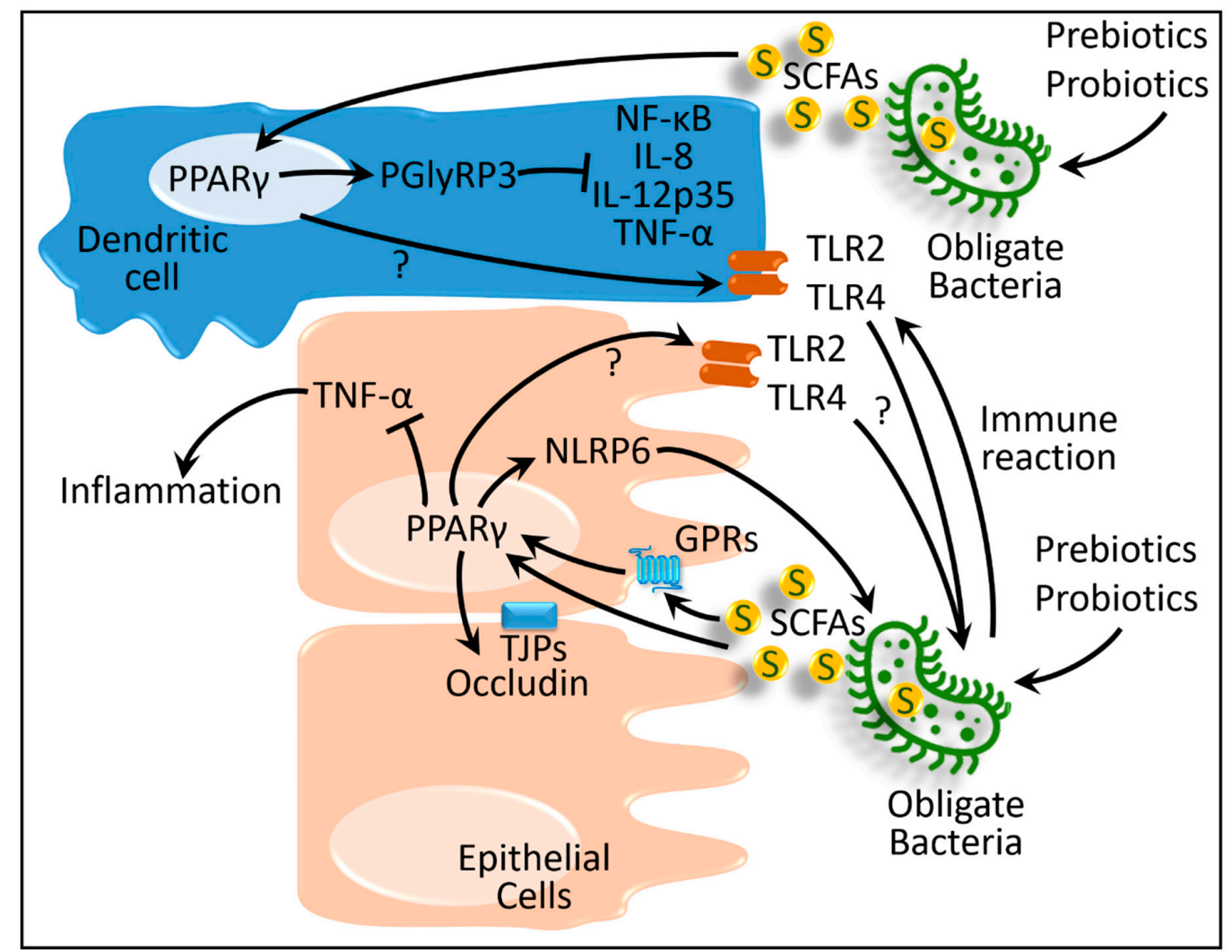

Figure 2. Schematic presentation of interactions between host PPARs and gut microbiota in gastrointestinal disease. GPRs, G-protein-coupled receptors; IL, interleukin; NF- $\kappa \mathrm{B}$, nuclear factor $\kappa \mathrm{B}$; NLRP6, nucleotide-binding oligomerization domain protein-like receptors, pyrin-domain containing 6; PGlyRP3, peptidoglycan recognition protein 3; PPAR $\gamma$, peroxisome proliferator-activated receptor $\gamma$; S and SCFAs: short-chain fatty acids; TJPs, tight junction proteins; TLR, Toll-like receptor; TNF- $\alpha$, tumor necrosis factor $\alpha$. '?' denotes the contradictory or ambiguous evidences in the literatures. Black lines ending in arrowheads denote activation and lines ending in bars represent inhibition.

In intestinal epithelial cells and dendritic cells, the expressions of pattern recognition receptors, such as Toll-like receptors (TLR)-2 and -4 , along with some inflammatory cytokines (IL-18 and IL-1 $\beta)$, are increased in both irritable bowel syndrome and inflammatory bowel diseases $[50,55,57,62]$. Oligosaccharide treatment increases TLR2 and TLR4 in inflammatory bowel disease [55,57]. It was, therefore, postulated that TLRs play some protective roles by facilitating recognition of local microbiota and enhancing homeostasis along with providing cytoprotective effects $[50,63]$. The combined anti-inflammatory effects produced by PPARs, along with the TLR-mediated cytoprotective effects, might be beneficial for inflammatory bowel diseases; however, further clarification is required to explore the microbiota-PPAR-TLR interactions in inflammatory bowel diseases and irritable bowel syndrome. 
All the abovementioned studies in this section postulate that PPARs (1) activate the intestinal epithelial tight junction protein occludin, (2) increase intestinal NLRP6 to reverse intestinal inflammation, (3) increase anti-inflammatory PGlyRP3 and decrease proinflammatory cytokines such as, IL-8, IL-12p35, and TNF- $\alpha$, and (4) possibly activate TLR2 and TLR4 to a certain level to allow the growth of the facultative microbiota. These balanced pro- and anti-inflammatory actions of PPARs thereby control bowel disorders (Figure 2).

\subsection{Effects of Gut Microbiota and PPAR Interactions in Obesity and Metabolic Syndrome}

Metabolic syndrome (MetS) is a complex of diseases broadly comprising dyslipidemia, insulin resistance, and type 2 diabetes mellitus. Obesity is a major predisposing factor of MetS [17,20]. Adipose tissue is the specialized organ that efficiently deposits extra energy as fat during nutritional excess and is used for releasing energy in times of nutritional deprivation. However, adipose tissue also acts as an active endocrine organ, maintaining whole-body energy homeostasis by releasing many adipocytokines such as adiponectin. However, in times of continuous nutritional overload, adipose tissue becomes hypertrophic and hyperplastic [64,65]. The hypertrophic adipocytes release inflammatory adipocytokines, such as IL-6, TNF- $\alpha$, etc., creating a low-grade inflammatory milieu $[20,66]$. This inflammatory state is considered a major predisposing factor for obesity-induced pathogeneses $[17,20]$.

In addition to adipose tissue dysfunction, dysbiosis of intestinal microbiota can initiate a similar inflammatory milieu that predisposes a person to metabolic disorders [67]. As mentioned in different instances within this review, a notable feature of obesity-induced intestinal dysbiosis is an increase in Firmicutes phyla and a decrease in Bacteroidetes phyla [68,69]. However, Firmicutes are Gram-positive and Bacteroidetes are Gram-negative bacteria. Therefore, a low abundance of Gram-negative Bacteroidetes in obesity should reduce serum lipopolysaccharide levels, an endotoxin mostly produced by Gram-negative bacteria. Thus, the causative role of microbiota in low-grade inflammation, as seen in obesity, cannot merely be explained by the reduction in Bacteroidetes [67]. In type 2 diabetes patients, in addition to Firmicutes, lipopolysaccharide-producing E. coli (phylum Proteobacteria) also increases [69]. This latter species may contribute to enhanced systemic inflammation of the intestine. In this dysbiosis, gut permeability is also impaired due to reduced expression of enterocyte tight junction regulators such as zonula occludens- 1 and occludin. As a result, lipopolysaccharide can be easily transported in the circulation system [70].

In this regard, some chemical compounds aimed at activating PPAR $\gamma$ were shown to reverse high-fat diet-induced dysbiosis of the gut microbiota. Salvia miltiorrhiza, a plant-derived tanshinol borneol ester (Danshensu Bingpian Zhi, DBZ), is a synthetic derivative of natural compounds. DBZ is an activator of PPAR $\gamma$; however, the potency is lower than thiazolidinedione. In a high-fat diet-induced, obesity-related MetS mouse model, DBZ reduced the high-fat diet-induced increased Firmicutes-to-Bacteroidetes ratio. In MetS, the abundance of Firmicutes population upregulates the intestinal absorption and metabolism of fatty acids, which increases the intestinal lipid droplet number [71]. Alternatively, in lean animals, a low abundance of Firmicutes or some other species decreases dietary carbohydrate processing, inhibits excess energy absorption, and reduces lipogenesis [72]. DBZ increases Akkermansia, which are beneficial bacteria belonging to phylum Verrucomicrobia, and suppresses high-fat diet-induced harmful bacteria, including Helicobacter marmotae, Odoribacter, and Anaerotruncus. Therefore, DBZ-mediated PPAR $\gamma$ activity improves high-fat diet-induced dysbiosis, weight gain, and insulin resistance in diabetic mice [73].

As a mechanism, gut microbes convert dietary fibers such as pyruvate, succinate, and lactate into short-chain fatty acids, such as acetate, butyrate, and propionate. Fatty acids bind with specific G-protein-coupled receptors, such as GPR109A, GPR41, and GPR43, or can directly activate nuclear receptors such as PPARs and initiate several biological actions [32,74]. In the intestine, butyrate suppress proinflammatory macrophages, propionate enhances satiety, and acetate affects adipose tissue, brain, and liver, and improves metabolic effects [32]. Short-chain fatty acids, even acetylate and 
methylate histone, modify the chromatin structure and epigenetically regulate genes involved in PPAR signaling and diabetes mellitus [5]. Another line of evidence suggests that obese subjects with higher insulin resistance and fasting serum triglyceride levels show lower bacterial gene abundance than lean subjects (379,436 and 567,499 genes for obese and lean subjects, respectively) [75]. Presumably, the low abundance of microbial genes results from a reduction in butyrate-producing bacteria [76]. Thereby, high-calorie diets reduce microbial short-chain fatty acid production, whereas energy-restricted diets improve the gene richness in obese subjects, along with reducing overall obesity trends of fat mass, circulating cholesterol and, to some extent, inflammation $[5,76]$. Through these mechanisms, short-chain fatty acids produced by the microbiota alter the metabolic state through PPAR signaling (Figure 3).

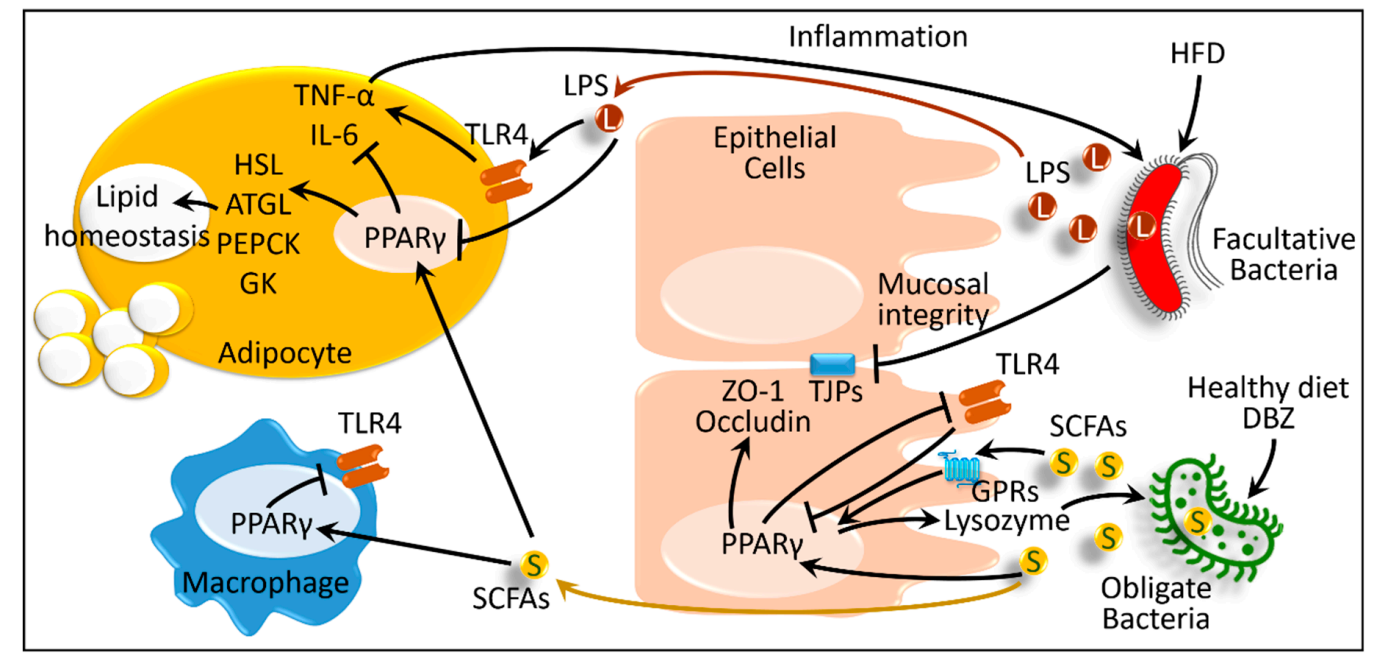

Figure 3. Schematic presentation of interactions between host PPARs and gut microbiota in obesity and metabolic syndrome. ATGL, adipose triglyceride lipase; DBZ, tanshinol borneol ester Danshensu Bingpian Zhi; GK, glycerol kinase; GPRs, G-protein-coupled receptors; HFD, high-fat diet; HSL, hormone-sensitive lipase; IL, interleukin; L and LPS, lipopolysaccharide; PEPCK, phosphoenolpyruvate carboxykinase; PPAR $\gamma$, peroxisome proliferator-activated receptor $\gamma$; S and SCFAs: short-chain fatty acids; TJPs, tight junction proteins; TLR, Toll-like receptor; TNF- $\alpha$, tumor necrosis factor $\alpha$; ZO-1, zonula occludens-1. Black lines ending in arrowheads denote activation and lines ending in bars represent inhibition. Yellow and red arrows depict absorption of short-chain fatty acids and lipopolysaccharide, respectively.

However, not only the variations in species, but also different strains of bacteria play diverse roles in obesity. Helicobacter pylori is a dominant gastric microbiota. Excessive presence of H. pylori in the stomach and duodenum commonly predisposes a person to peptic ulcer disease [77]. However, a strain containing mutated cytotoxin-associated gene pathogenicity island (cag PAI) is associated with increased PPAR $\gamma$ activation and upregulation of its target genes (i.e., CD36 and fatty-acid-binding protein 4) in a mouse model. Mice infected with this strain show enhanced influx of regulatory T cells into white adipose tissue during obesity. However, humans are always colonized by both strains [78]. The cag PAI mutated strain provides protection against metabolic disorders by augmenting anti-inflammatory responses [79]. Therefore, disappearance of gastric $H$. pylori due to consumption of antibiotics may, at least in part, contribute to enhanced epidemics of obesity and other related metabolic disorders [79].

The assumption about dysbiosis in the context of MetS is partly TLR4-centered. In MetS, inflammasomes (i.e., lipopolysaccharides) activate TLR4 in adipocytes and inflammatory cells, thus inducing the inflammatory milieu in obesity [70]. In addition to adipose tissue, in MetS, intestinal epithelial TLR4 dysregulation plays a vital role. In an experimental mouse model, inactivation of TLR4 only in the intestine, but not the whole body, instigates MetS. Intestinal TLR4 deficiency downregulates 
$\operatorname{PPAR} \gamma$ and the antimicrobial peptide lysozyme expressions in the intestine [80]. Due to the lack of antimicrobial lysozyme, the bacterial population also alters; thus, microbial genes involved in the metabolism of lipids, amino acids, and nucleotides are also dysregulated. PPAR $\gamma$ deficiency itself predisposes a person to MetS. However, the PPAR $\gamma$ agonist (i.e., rosiglitazone) ameliorates the dysbiosis and the metabolic abnormality [80]. Therefore, PPAR $\gamma$ activity reverses the pro-inflammatory effects of intestinal epithelial receptors, such as TLR4, thus maintaining intestinal microbial homeostasis as an additional mechanism to ameliorate MetS.

Taken together, high-caloric diets alter the intestine microbial homeostasis plausibly through the TLR4-PPAR $\gamma$-mediated pathway. This alteration leads to (1) an increase in the inflammasome (lipopolysaccharide)-producing microbial population, and (2) a decrease in the short-chain fatty-acid-producing microbes. As a result, systemic inflammation increases while short-chain fatty-acid production decreases. Short-chain fatty acids activate PPARs in various organs, including adipose tissue, to modulate lipolytic genes such as hormone-sensitive lipase, adipose triglyceride lipase, and lipogenic genes such as phosphoenolpyruvate carboxykinase and glycerol kinase; they also help properly metabolize and utilize fat $[32,65,81]$. However, due to a lack of short-chain fatty acids, PPAR activity also decreases, which causes accumulation of excess fat in obesity. Therefore, restoration of the microbial population restores the whole pathway and eventually activates PPARs, thus improving obesity (Figure 3).

\subsection{Effects of Gut Microbiota and PPAR Interactions in Liver Diseases}

In western and Middle Eastern countries, non-alcoholic fatty liver disease is the most common type of chronic liver disease [82]. The major predisposing factors of non-alcoholic fatty liver disease are an excessive supply of fatty acids in the liver and impaired disposal of lipids from the liver. Obesity with dyslipidemia is typically associated with non-alcoholic fatty liver disease [82-84]. In obesity, excessive fatty acids are released into circulation via lipolysis of triglycerides from the adipocytes. Absorption of dietary fatty acids from the intestine increases, as does de novo lipogenesis in the liver. Thus, the supply of lipids to the liver increases $[20,85]$. The excessive surge of lipids eventually provokes endoplasmic reticulum stress in the hepatocytes, thus leading to hepatocellular injury [86]. In parallel, mitochondrial $\beta$-oxidation and esterification, which forms triglycerides, are also impaired in non-alcoholic fatty liver disease [86].

As primary metabolic energy substrates, carbohydrates and fatty acids are excessively present in obesogenic diets. Fat- and carbohydrate-restricted diets emerged as effective dietary interventions for non-alcoholic fatty liver disease [86]. In the process, the intestinal microbiota plays some critical roles. In obese subjects with non-alcoholic fatty liver disease, when maintained on isocaloric low-carbohydrate diet for seven days, the numbers of folate-producing Streptococcus and Lactococcus markedly increase. As a result, serum folate level also increases [87]. Folate upregulates the expression of genes involved in folate-dependent one-carbon metabolism (i.e., $\beta$-hydroxybutyrate) and through some intermediate products, folate generates glutathione. As an antioxidant, glutathione maintains $\beta$-oxidation. Additionally, hepatic expression of PPAR $\alpha$ and its downstream genes involved in $\beta$-oxidation increases in these obese subjects [87]. Although humans require daily folate intake, it can be produced from consumed milk products via the activity of Streptococcus, Lactococcus, and Bifidobacterium species [88]. Thus, low-carbohydrate diets improve non-alcoholic fatty liver disease, at least in part, by increasing folate-producing bacterial population in the gut and folate-induced PPAR $\alpha$-mediated $\beta$-oxidation in the liver.

High-fat diet-fed mice models usually show liver steatosis associated with an increase of phyla Firmicutes, Proteobacteria, and Verrucomicrobia [89,90]. Members of Proteobacteria express endotoxins and produce lipopolysaccharides, whereas members of Firmicutes (Erysipelotrichaceae) and Verrucomicrobia (Akkermansia muciniphila) degrade the mucus barrier [91]. Together, this form of dysbiosis results in increased circulating inflammatory mediators, such as TLR4, IL-6, and TNF- $\alpha$, along with endotoxemia [92-94]. Bacteroidetes, Lactobacillus, and Parabacteroides populations decrease 
in such pathogeneses [90]. Lactobacillus (Lactobacillus rhamnosus GG and Lactobacillus platarum WCFS1) show protective effects against non-alcoholic fatty liver disease [90]. In this study, Lactobacillus strains reversed the high-fat diet-induced dysbiosis such that not only Lactobacillus, but also Bacteroidetes and Parabacteroides populations increased. This alteration of symbiosis was associated with reversal of the epithelial barrier integrity and improved intestinal barrier function through upregulated expression of intestinal tight junction protein occludin and zonula occludens-1. The levels of endotoxemia and hepatic steatosis were also reversed by the Lactobacillus. In the presence of the anthraquinone from a herb named Cassia obtusifolia L., all these improvements were further augmented [90]. The authors showed that these treatments enhanced hepatic expressions of PPAR $\alpha$ while decreasing the expressions of PPAR $\gamma, \beta$-hydroxy $\beta$-methylglutaryl co-enzyme A (HMG-CoA) reductase, and sterol regulatory element-binding protein-1c (Figure 4) [90].

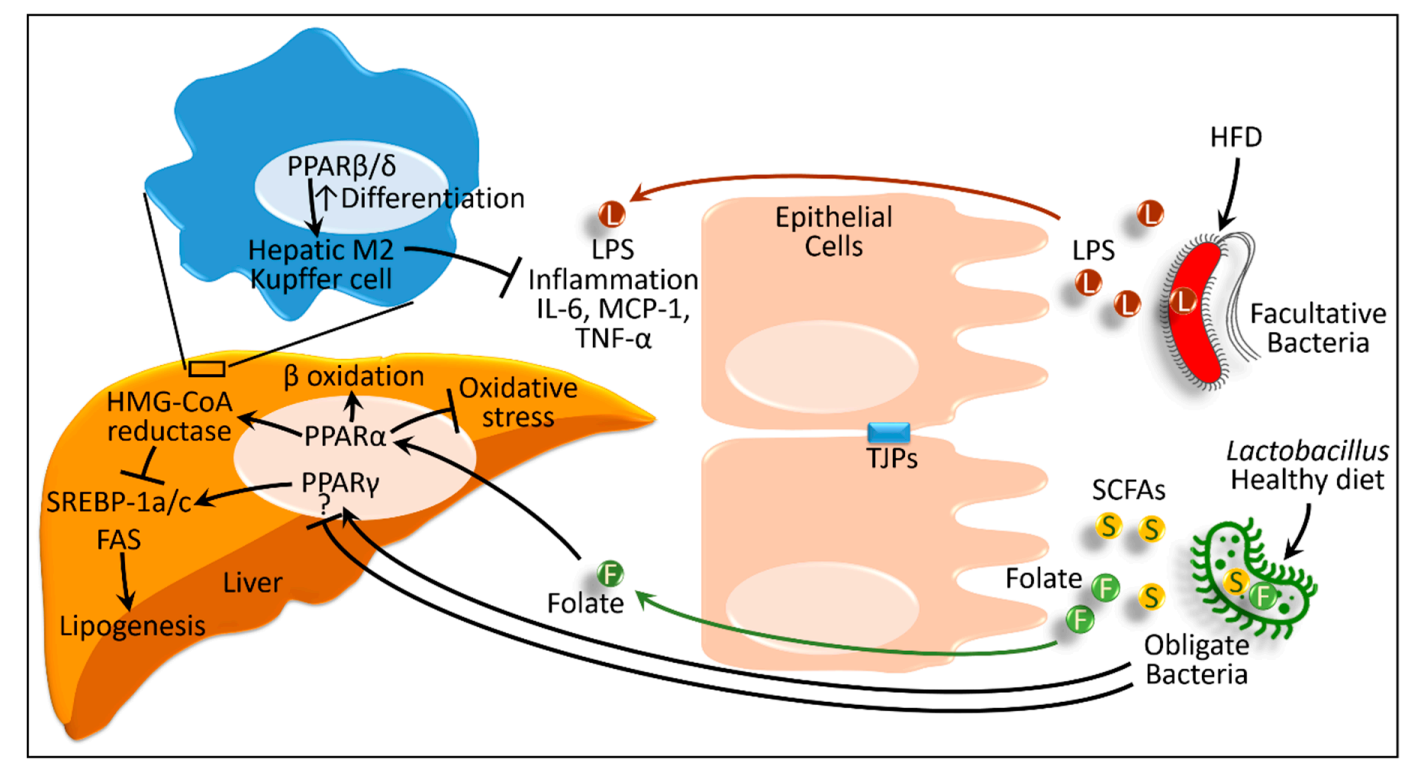

Figure 4. Schematic presentation of interactions between host PPARs and gut microbiota in obesity and metabolic syndrome. F, Folate; FAS, fatty acid synthase; HFD, high-fat diet; HMG-CoA, $\beta$-hydroxy $\beta$-methylglutaryl co-enzyme A; IL, interleukin; L and LPS, lipopolysaccharide; MCP-1, monocyte chemoattractant protein 1; PPAR, peroxisome proliferator-activated receptors $(\alpha, \beta / \delta$, and $\gamma)$; S and SCFAs: short-chain fatty acids; SREBP, sterol regulatory element-binding protein; TJPs, tight junction proteins; TNF- $\alpha$, tumor necrosis factor $\alpha$. '?' denotes the contradictory or ambiguous evidences in the literatures. Black lines ending in arrowheads denote activation and lines ending in bars represent inhibition. Green and red arrows depict absorption of folate and lipopolysaccharide, respectively.

Similarly, continuous consumption of a fructose-rich diet induces non-alcoholic fatty liver disease-like changes and insulin resistance in animal models. Lactobacillus (Lactobacillus casei and Lactobacillus reuteri GMNL-263) treatment activates hepatic PPAR $\gamma$ and attenuates inflammatory mediators, such as TLR4, IL-6, and TNF- $\alpha$, which subsequently attenuates steatosis [93,94]. Lactobasillus decreases expression of several lipogenic genes (sterol regulatory element-binding protein-1a and fatty-acid synthase). This PPAR $\gamma$-mediated change caused by Lactobacillus has promising therapeutic potential in obesity-mediated type 2 diabetes mellitus and associated non-alcoholic fatty liver disease [94]. In this regard, Alves et al. showed that, in the hypercholesteremic mice model, symbiotic strains (Lactobacillus paracasei Lpc-37, Lactobacillus rhamnosus HN001, Lactobacillus acidophilus NCFM, and Bifidobacterium lactis HN019) and prebiotic fructo-oligosaccharides enhanced $\beta$-oxidation through PPAR $\alpha$, as well as reduced lipogenesis through sterol regulatory element-binding protein-1c. As a result, hypercholesterolemia-induced non-alcoholic fatty liver disease-like changes in the liver were improved [95]. 
Lactobacillus (Lactobacillus paracasei) also induces proliferation of hepatic $\mathrm{F} 4 / 80^{+} \mathrm{CD} 206^{+}$cells (macrophage 2 (M2) Kupffer cells) [96]. The classical variants of macrophages (M1) activate non-alcoholic fatty liver disease, whereas the regulatory circuit that stimulates differentiation of the alternative variant (M2) suppresses steatosis. In general, the alternative activation of macrophages (M2 subgroup) accounts for anti-inflammatory effects [97]. For non-alcoholic fatty liver disease or non-alcoholic steatohepatitis, the alternative variant of macrophage (M2 Kupffer cells) is proposed to have protective effects. In the process, PPAR $\beta / \delta$ in Kupffer cells presumably induces the alternative activation of the M2 phenotype [98].

Not only non-alcoholic steatohepatitis, but also the anti-inflammatory effects of Lactobacillus (Lactobacillus casei Zhang) were observed in a lipopolysaccharide- and D-galactosamine-induced acute liver failure rat model [99]. In this model, Lactobacillus increased the expression of PPAR $\gamma$ and attenuated TLR2, and TLR9 triggered phosphorylation of extracellular signal-regulated kinase (ERK), c-Jun N-terminal kinase (JNK), p38, and mitogen-activated protein kinase (MAPK) and prevented intestinal injury and increased fecal Lactobacillus and Bifidobacterium levels [99].

In contrast to the abovementioned studies, germ-free mice inoculated with feces from non-alcoholic steatohepatitis patients and fed a high-fat diet showed an increase in abundance of Lactobacillus [100]. Each probiotic has distinct effects on lipid metabolism and, thus, differentially affects the liver and other organs. More specifically, in lean animals, Lactobacillus fermentum and Lactobacillus ingluviei cause weight gain, whereas, in obese animals, L. gasseri and L. plantarum have anti-obesity effects $[101,102]$. The effects can be explained by the fact that each microbiota has its own capacity to metabolize nutrients and release substrates that are absorbed and used by the body. Chiu et al. showed that the hepatic expression of PPAR $\gamma$ along with inflammatory markers (IL-6, monocyte chemoattractant protein 1, TLR2, TLR4, and TNF- $\alpha$ ) increased in the mice that received microbiota from non-alcoholic steatohepatitis patients and were fed a high-fat diet [100]. This study further proves that it is important to carefully choose microbial strains when planning clinically applicable probiotic regimens.

We observe that, although the effects of PPAR $\gamma$ show some ambiguities, PPAR $\gamma$, along with $\operatorname{PPAR} \alpha$ and $\operatorname{PPAR} \beta / \delta$, plays some interesting roles in the liver. Effects of endotoxin-producing microbes disrupt intestinal integrity and activate systemic inflammatory responses, which result in steatosis or steatohepatitis. As a systemic effect, some microbes, such as Lactobacillus, (1) attenuate the inflammatory responses, and (2) facilitate functions of PPARs in hepatic and Kupffer cells to restore hepatic pathogeneses. The microbes also enhance production of some metabolites (such as folate) and activate hepatic PPAR $\alpha$. PPAR $\alpha$ activation (1) enhances $\beta$-oxidation of fatty acids, (2) decreases lipogenesis, and (3) reduces oxidative stress. Thereby, PPARs protect against non-alcoholic hepatic steatosis and steatohepatitis (Figure 4).

\subsection{Effects of Gut Microbiota and PPAR Interactions in the Cardiovascular System}

The work by Mencarelli et al. [103] expanded our understanding of the effect of gut microbiota from non-alcoholic steatohepatitis on atherosclerosis using the apolipoprotein $\mathrm{E}$ (ApoE)-deficient mice model. This mouse model is widely used to study hyperlipidemia-associated atherosclerosis. Exposing these mice to dextran sodium sulfate caused breaking of the intestinal barrier and transition from steatosis to non-alcoholic steatohepatitis [103]. These ApoE-deficient mice showed severe atherosclerotic lesions, insulin resistance, and features of steatohepatitis. Treating these mice with VSL\#3, a mixture of eight probiotic strains (Lactobacillus plantarum, Lactobacillus delbrueckii subsp. bulgaricus, Lactobacillus casei, Lactobacillus acidophilus, Bifidobacterium breve, Bifidobacterium longum, Bifidobacterium infantis, and Streptococcus salivarius subsp. thermophilus) [53] significantly attenuated the atherosclerotic plaque produced by dextran sodium sulfate. $\mathrm{CD}^{+} \mathrm{B}$ lymphocytes isolated from the spleen showed that VSL\#3 reversed the dextran-sodium-sulfate-induced phenotype changes to a less inflammatory phenotype. Messenger RNA (mRNA) expression of PPAR $\gamma$ increased in the gut epithelium, and conditioned media collected from the growth of VSL\#3 enhanced the luciferase 
reporter activity of PPAR $\gamma$ in HepG2 hepatocytes. This study suggested that probiotics regulate intestinal inflammation and protect against steatohepatitis and atherosclerosis through increasing hepatic and intestinal PPAR $\gamma$ (Figure 5) [103].

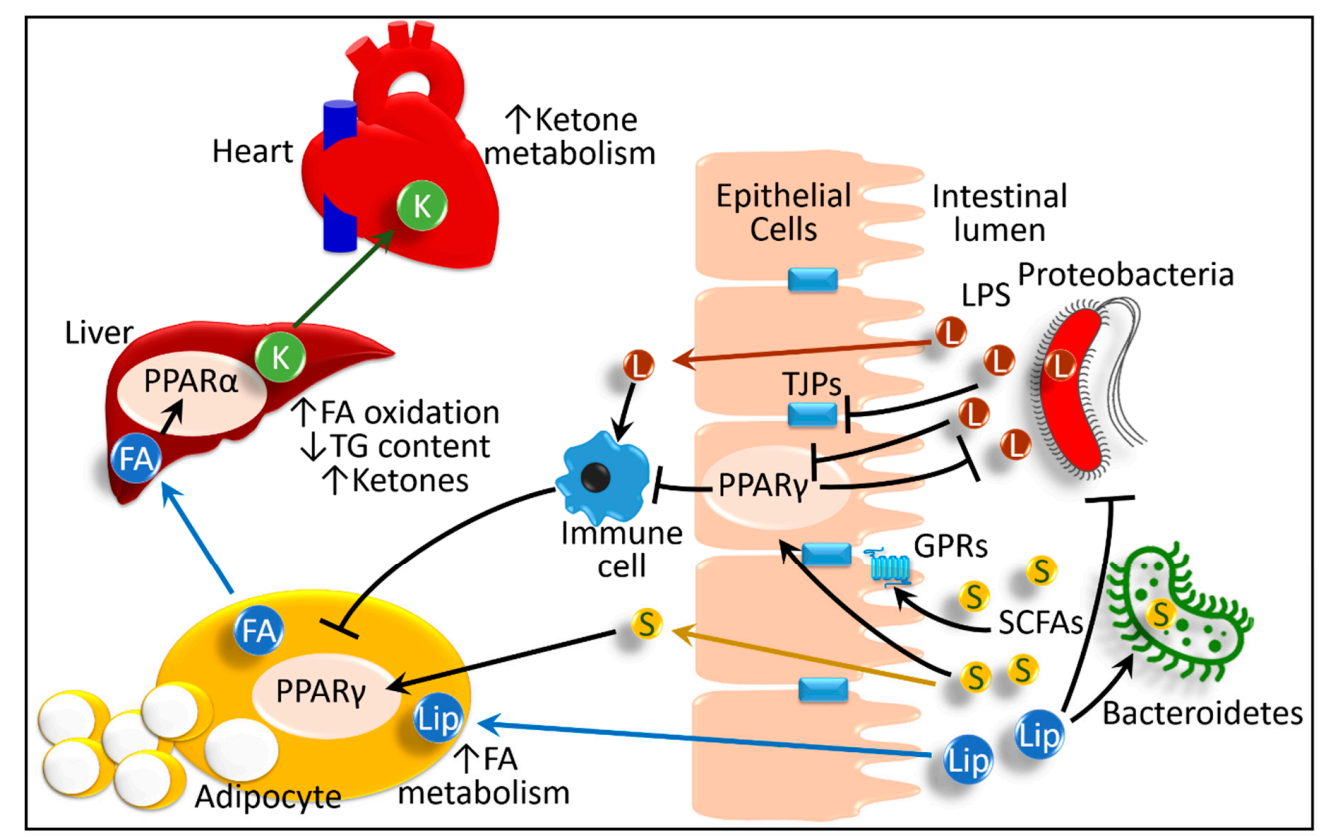

Figure 5. Schematic presentation of interactions between host PPARs and gut microbiota in health and disease. A healthy diet maintains a normal microbial population, that is, more beneficial short-chain fatty acid (S)-producing Bacteroidetes phyla. The short-chain fatty acids activate their respective G-protein-coupled receptors (GPRs), as well as PPAR $\gamma$, in the intestinal epithelium. These processes activate tight junction proteins (TJPs) and maintain intestinal integrity. PPAR $\gamma$ retains the immune cell response at the physiologic level adequate to maintain microbial homeostasis. In healthy conditions, adipose tissue metabolizes lipid (Lip) and sustains serum fatty-acid (FA) levels through PPAR $\gamma$ activity. Hepatic PPAR $\alpha$ sustains fatty acids through activating $\beta$-oxidation. The liver also produces ketone bodies $(\mathrm{K})$, which are used by the heart as a source of high energy. However, high-fat diets cause dysbiosis and increase lipopolysaccharide-producing Proteobacteria phyla. Lipopolysaccharides and other inflammatory molecules activate local and systemic inflammatory responses and cause leakage of inflammatory mediators into the circulatory system. This process predisposes people to intestinal abnormalities such as inflammatory bowel disease and irritable bowel syndrome. The inflammatory response hampers lipid metabolism in adipose tissue and liver. These cause obesity, metabolic abnormalities, atherosclerosis, and non-alcoholic fatty liver diseases. Taken together, these processes account for additional mechanisms of microbiota-induced bowel diseases, metabolic syndrome, type 2 diabetes mellitus, and atherosclerosis. FA, fatty acids; GPRs, G-protein-coupled receptors; K, ketone bodies; Lip, lipids; L and LPS, lipopolysaccharide; PPAR, peroxisome proliferator-activated receptors $(\alpha$ and $\gamma$ ); S and SCFAs: short-chain fatty acids; TJPs, tight junction proteins. Black lines ending in arrowheads denote activation and lines ending in bars represent inhibition. Blue arrows represent transportation of lipids and fatty acids. Green arrow depict mobilization and yellow arrow depicts absorption of short-chain fatty acids.

Similar to energy excess, in states of energy deprivation, the microbiota plays an interesting role in the heart. Fasting for 24 hours causes a shift in microbiota toward an increase in Bacteroidetes (42.3\% in fasted vs. $20.6 \%$ in fed mice) and a decrease in Firmicutes (52.6\% in fasted vs. $77.1 \%$ in fed mice) [104]. This pattern is the opposite from that generally observed in high-fat feeding: a decrease in Bacteroidetes and an increase in Firmicutes phyla [68,69]. Mice transplanted with microbiota collected from distal gut show higher serum $\beta$-hydroxybutyrate, a ketone ester [105], than the mice devoid of gut microbiota. During fasting, the bacteria-transplanted mice showed high hepatic triglyceride stores and 
higher PPAR $\alpha$ expression in their liver, along with increased production of hepatic $\beta$-hydroxybutyrate. However, the fasting-induced ketogenic response, such as serum $\beta$-hydroxybutyrate level and hepatic expression of 3-hydroxy-3-methylglutaryl-CoA synthase, a PPAR $\alpha$-responsive ketogenic enzyme, is blunted in PPAR $\alpha$ knock-out mice. These findings suggest that the effect of gut microbiota on fasting-induced ketosis involves PPAR $\alpha$ [104]. The authors proposed that fasted mice containing gut microbiota produce and absorb more acetate, which acts as a substrate for increasing the hepatic triglyceride level. This triglyceride enhances production of ketone bodies in the liver and their release into circulation [104]. Due to its high energy demand, the heart can produce and use energy either through oxidation of fatty acids or from ketone bodies [105]. Between them, the use of ketone bodies is more energetically efficient and yields more energy. Therefore, during fasting, the higher level of ketone bodies, produced from the liver of the mice containing gut microbiota, acts as a highly efficient and ready source of energy for the heart. In this beneficial effect of gut microbiota on the heart during fasting, hepatic PPAR $\alpha$-mediated production of ketone bodies plays a pivotal role (Figure 5) [104].

Endothelial nitric oxide synthase and nitric oxide (eNOS-NO) signaling is vital for maintaining cardiac function, as well as for protecting against atherosclerosis. Nitric oxide, produced from the myocardium or from any extrinsic sources, regulates the heart rate and force of contraction, and also helps remodel the heart after myocardial infarction [106,107]. PPARs, in particular PPAR $\alpha$, activate nitric oxide production in these tissues [108]. Therefore, in some cardiovascular dysfunctions, intestinal microbiota-derived short-chain fatty acids such as butyrate presumably contribute to improving cardiovascular pathogeneses [108]. However, gut microbiota can produce some metabolites, such as trimethylamine $\mathrm{N}$-oxide (TMAO), which are known to develop atherosclerosis, heart failure, and peripheral artery diseases [109]. As the exact mechanisms through which PPARs and the microbiota regulate or dysregulate cardiovascular functions remain controversial, further studies are required to better elucidate these pathways.

\section{Conclusions and Perspective}

In this review, we confined our discussion to limited types of diseases: those related to digestion, immunity, and metabolism. In these fields, microbiota-based therapeutic approaches show promise as remedies for many currently incurable diseases such as type 2 diabetes mellitus, non-alcoholic fatty liver diseases, irritable bowel syndrome, and inflammatory bowel disease. The concepts of microbiota-based therapeutic approaches are gradually changing: from changing dietary habits to modulating microbiota [10], to ingesting some probiotic strains, to producing beneficial short-chain fatty acids [32]. Novel concepts, such as ingesting genetically engineered bacteria to deliver specific bioactive small molecules and regulating host $G$ protein-coupled receptors, are emerging [8]. Despite the limited clinical trials and laboratory-based findings remaining far from introducing effective therapies, the therapeutic benefits of microbiota through the modulation of PPARs remain pivotal.

Author Contributions: A.U.H. and H.K. designed this study. A.U.H. gathered the data and wrote the manuscript. A.R. and H.K. revised the manuscript.

Funding: This research was supported by the internal research fund for the researchers of the International University of Health and Welfare, awarded to A.U.H.

Acknowledgments: We cordially thank our colleagues who encouraged the work.

Conflicts of Interest: The authors declare no conflict of interest.

\section{References}

1. Pflughoeft, K.J.; Versalovic, J. Human microbiome in health and disease. Annu. Rev. Pathol. 2012, 7, 99-122. [CrossRef] [PubMed]

2. Watson, M.M.; Søreide, K. Chapter 32-The Gut Microbiota Influence on Human Epigenetics, Health, and Disease. In Handbook of Epigenetics, 2nd ed.; Tollefsbol, T.O., Ed.; Academic Press: Cambridge, MA, USA, 2017; pp. 495-510. ISBN 978-0-12-805388-1. 
3. Lozupone, C.A.; Stombaugh, J.; Gonzalez, A.; Ackermann, G.; Wendel, D.; Vazquez-Baeza, Y.; Jansson, J.K.; Gordon, J.I.; Knight, R. Meta-analyses of studies of the human microbiota. Genome Res. 2013, 23, 1704-1714. [CrossRef] [PubMed]

4. Qin, J.; Li, R.; Raes, J.; Arumugam, M.; Burgdorf, K.S.; Manichanh, C.; Nielsen, T.; Pons, N.; Levenez, F.; Yamada, T.; et al. A human gut microbial gene catalogue established by metagenomic sequencing. Nature 2010, 464, 59-65. [CrossRef] [PubMed]

5. Krautkramer, K.A.; Kreznar, J.H.; Romano, K.A.; Vivas, E.I.; Barrett-Wilt, G.A.; Rabaglia, M.E.; Keller, M.P.; Attie, A.D.; Rey, F.E.; Denu, J.M. Diet-Microbiota Interactions Mediate Global Epigenetic Programming in Multiple Host Tissues. Mol. Cell 2016, 64, 982-992. [CrossRef]

6. Cohen, L.J.; Esterhazy, D.; Kim, S.H.; Lemetre, C.; Aguilar, R.R.; Gordon, E.A.; Pickard, A.J.; Cross, J.R.; Emiliano, A.B.; Han, S.M.; et al. Commensal bacteria make GPCR ligands that mimic human signalling molecules. Nature 2017, 549, 48-53. [CrossRef] [PubMed]

7. Asano, Y.; Hiramoto, T.; Nishino, R.; Aiba, Y.; Kimura, T.; Yoshihara, K.; Koga, Y.; Sudo, N. Critical role of gut microbiota in the production of biologically active, free catecholamines in the gut lumen of mice. Am. J. Physiol. Gastrointest. Liver Physiol. 2012, 303, G1288-G1295. [CrossRef] [PubMed]

8. Sharkey, K.A.; Beck, P.L.; McKay, D.M. Neuroimmunophysiology of the gut: Advances and emerging concepts focusing on the epithelium. Nat. Rev. Gastroenterol. Hepatol. 2018, 15, 765-784. [CrossRef] [PubMed]

9. Ghaisas, S.; Maher, J.; Kanthasamy, A. Gut microbiome in health and disease: Linking the microbiome-gut-brain axis and environmental factors in the pathogenesis of systemic and neurodegenerative diseases. Pharmacol. Ther. 2016, 158, 52-62. [CrossRef] [PubMed]

10. Borody, T.J.; Khoruts, A. Fecal microbiota transplantation and emerging applications. Nat. Rev. Gastroenterol. Hepatol. 2011, 9, 88-96. [CrossRef] [PubMed]

11. Stensvold, C.R.; van der Giezen, M. Associations between Gut Microbiota and Common Luminal Intestinal Parasites. Trends Parasitol. 2018, 34, 369-377. [CrossRef] [PubMed]

12. Schupp, M.; Lazar, M.A. Endogenous ligands for nuclear receptors: Digging deeper. J. Biol. Chem. 2010, 285, 40409-40415. [CrossRef] [PubMed]

13. Bensinger, S.J.; Tontonoz, P. Integration of metabolism and inflammation by lipid-activated nuclear receptors. Nature 2008, 454, 470-477. [CrossRef] [PubMed]

14. Issemann, I.; Green, S. Activation of a member of the steroid hormone receptor superfamily by peroxisome proliferators. Nature 1990, 347, 645-650. [CrossRef] [PubMed]

15. Tontonoz, P.; Hu, E.; Graves, R.A.; Budavari, A.I.; Spiegelman, B.M. mPPAR gamma 2: Tissue-specific regulator of an adipocyte enhancer. Genes Dev. 1994, 8, 1224-1234. [CrossRef]

16. Kliewer, S.A.; Forman, B.M.; Blumberg, B.; Ong, E.S.; Borgmeyer, U.; Mangelsdorf, D.J.; Umesono, K.; Evans, R.M. Differential expression and activation of a family of murine peroxisome proliferator-activated receptors. Proc. Natl. Acad. Sci. USA 1994, 91, 7355-7359. [CrossRef] [PubMed]

17. Corrales, P.; Vidal-Puig, A.; Medina-Gómez, G. PPARs and Metabolic Disorders Associated with Challenged Adipose Tissue Plasticity. Int. J. Mol. Sci. 2018, 19, 2124. [CrossRef]

18. Evans, R.M.; Barish, G.D.; Wang, Y.X. PPARs and the complex journey to obesity. Nat. Med. 2004, 10, $355-361$. [CrossRef]

19. Tyagi, S.; Gupta, P.; Saini, A.S.; Kaushal, C.; Sharma, S. The peroxisome proliferator-activated receptor: A family of nuclear receptors role in various diseases. J. Adv. Pharm. Technol. Res. 2011, 2, 236-240. [CrossRef]

20. Gross, B.; Pawlak, M.; Lefebvre, P.; Staels, B. PPARs in obesity-induced T2DM, dyslipidaemia and NAFLD. Nat. Rev. Endocrinol. 2017, 13, 36-49. [CrossRef]

21. Savage, D.C. Microbial ecology of the gastrointestinal tract. Annu. Rev. Microbiol. 1977, 31, 107-133. [CrossRef]

22. Sender, R.; Fuchs, S.; Milo, R. Revised Estimates for the Number of Human and Bacteria Cells in the Body. PLoS Biol. 2016, 14, e1002533. [CrossRef] [PubMed]

23. Turnbaugh, P.J.; Hamady, M.; Yatsunenko, T.; Cantarel, B.L.; Duncan, A.; Ley, R.E.; Sogin, M.L.; Jones, W.J.; Roe, B.A.; Affourtit, J.P.; et al. A core gut microbiome in obese and lean twins. Nature 2009, 457, 480-484. [CrossRef] [PubMed]

24. De Filippo, C.; Cavalieri, D.; Di Paola, M.; Ramazzotti, M.; Poullet, J.B.; Massart, S.; Collini, S.; Pieraccini, G.; Lionetti, P. Impact of diet in shaping gut microbiota revealed by a comparative study in children from Europe and rural Africa. Proc. Natl. Acad. Sci. USA 2010, 107, 14691-14696. [CrossRef] [PubMed] 
25. Penders, J.; Thijs, C.; Vink, C.; Stelma, F.F.; Snijders, B.; Kummeling, I.; van den Brandt, P.A.; Stobberingh, E.E. Factors influencing the composition of the intestinal microbiota in early infancy. Pediatrics 2006, 118, 511-521. [CrossRef] [PubMed]

26. Rutayisire, E.; Huang, K.; Liu, Y.; Tao, F. The mode of delivery affects the diversity and colonization pattern of the gut microbiota during the first year of infants' life: A systematic review. BMC Gastroenterol. 2016, 16, 86. [CrossRef] [PubMed]

27. Are, A.; Aronsson, L.; Wang, S.; Greicius, G.; Lee, Y.K.; Gustafsson, J.A.; Pettersson, S.; Arulampalam, V. Enterococcus faecalis from newborn babies regulate endogenous PPARgamma activity and IL-10 levels in colonic epithelial cells. Proc. Natl. Acad. Sci. USA 2008, 105, 1943-1948. [CrossRef] [PubMed]

28. Zigmond, E.; Bernshtein, B.; Friedlander, G.; Walker, C.R.; Yona, S.; Kim, K.W.; Brenner, O.; Krauthgamer, R.; Varol, C.; Muller, W.; et al. Macrophage-restricted interleukin-10 receptor deficiency, but not IL-10 deficiency, causes severe spontaneous colitis. Immunity 2014, 40, 720-733. [CrossRef] [PubMed]

29. Kundu, P.; Ling, T.W.; Korecka, A.; Li, Y.; D'Arienzo, R.; Bunte, R.M.; Berger, T.; Arulampalam, V.; Chambon, P.; Mak, T.W.; et al. Absence of intestinal PPARgamma aggravates acute infectious colitis in mice through a lipocalin-2-dependent pathway. PLoS Pathog. 2014, 10, e1003887. [CrossRef] [PubMed]

30. Van den Bogert, B.; Erkus, O.; Boekhorst, J.; de Goffau, M.; Smid, E.J.; Zoetendal, E.G.; Kleerebezem, M. Diversity of human small intestinal Streptococcus and Veillonella populations. FEMS Microbiol. Ecol. 2013, 85, 376-388. [CrossRef] [PubMed]

31. Couvigny, B.; de Wouters, T.; Kaci, G.; Jacouton, E.; Delorme, C.; Dore, J.; Renault, P.; Blottiere, H.M.; Guedon, E.; Lapaque, N. Commensal Streptococcus salivarius Modulates PPARgamma Transcriptional Activity in Human Intestinal Epithelial Cells. PLoS ONE 2015, 10, e0125371. [CrossRef] [PubMed]

32. Koh, A.; De Vadder, F.; Kovatcheva-Datchary, P.; Backhed, F. From Dietary Fiber to Host Physiology: Short-Chain Fatty Acids as Key Bacterial Metabolites. Cell 2016, 165, 1332-1345. [CrossRef]

33. Laroui, H.; Ingersoll, S.A.; Liu, H.C.; Baker, M.T.; Ayyadurai, S.; Charania, M.A.; Laroui, F.; Yan, Y.; Sitaraman, S.V.; Merlin, D. Dextran sodium sulfate (DSS) induces colitis in mice by forming nano-lipocomplexes with medium-chain-length fatty acids in the colon. PLoS ONE 2012, 7, e32084. [CrossRef]

34. Simeoli, R.; Mattace Raso, G.; Lama, A.; Pirozzi, C.; Santoro, A.; Di Guida, F.; Sanges, M.; Aksoy, E.; Calignano, A.; D'Arienzo, A.; et al. Preventive and therapeutic effects of Lactobacillus paracasei B21060-based synbiotic treatment on gut inflammation and barrier integrity in colitic mice. J. Nutr. 2015, 145, 1202-1210. [CrossRef] [PubMed]

35. Donohoe, D.R.; Garge, N.; Zhang, X.; Sun, W.; O'Connell, T.M.; Bunger, M.K.; Bultman, S.J. The microbiome and butyrate regulate energy metabolism and autophagy in the mammalian colon. Cell Metab. 2011, 13, 517-526. [CrossRef] [PubMed]

36. Byndloss, M.X.; Olsan, E.E.; Rivera-Chavez, F.; Tiffany, C.R.; Cevallos, S.A.; Lokken, K.L.; Torres, T.P.; Byndloss, A.J.; Faber, F.; Gao, Y.; et al. Microbiota-activated PPAR-gamma signaling inhibits dysbiotic Enterobacteriaceae expansion. Science 2017, 357, 570-575. [CrossRef] [PubMed]

37. Lukovac, S.; Belzer, C.; Pellis, L.; Keijser, B.J.; de Vos, W.M.; Montijn, R.C.; Roeselers, G. Differential modulation by Akkermansia muciniphila and Faecalibacterium prausnitzii of host peripheral lipid metabolism and histone acetylation in mouse gut organoids. MBio 2014, 5. [CrossRef] [PubMed]

38. Shaw, M.H.; Kamada, N.; Kim, Y.G.; Nunez, G. Microbiota-induced IL-1beta, but not IL-6, is critical for the development of steady-state TH17 cells in the intestine. J. Exp. Med. 2012, 209, 251-258. [CrossRef]

39. Ivanov; Atarashi, K.; Manel, N.; Brodie, E.L.; Shima, T.; Karaoz, U.; Wei, D.; Goldfarb, K.C.; Santee, C.A.; Lynch, S.V.; et al. Induction of intestinal Th17 cells by segmented filamentous bacteria. Cell 2009, 139, 485-498. [CrossRef]

40. Ouyang, W.; Kolls, J.K.; Zheng, Y. The biological functions of T helper 17 cell effector cytokines in inflammation. Immunity 2008, 28, 454-467. [CrossRef]

41. Satoh-Takayama, N.; Vosshenrich, C.A.; Lesjean-Pottier, S.; Sawa, S.; Lochner, M.; Rattis, F.; Mention, J.J.; Thiam, K.; Cerf-Bensussan, N.; Mandelboim, O.; et al. Microbial flora drives interleukin 22 production in intestinal NKp46+ cells that provide innate mucosal immune defense. Immunity 2008, 29, 958-970. [CrossRef]

42. Zenewicz, L.A.; Yin, X.; Wang, G.; Elinav, E.; Hao, L.; Zhao, L.; Flavell, R.A. IL-22 deficiency alters colonic microbiota to be transmissible and colitogenic. J. Immunol. 2013, 190, 5306-5312. [CrossRef] [PubMed] 
43. Ota, N.; Wong, K.; Valdez, P.A.; Zheng, Y.; Crellin, N.K.; Diehl, L.; Ouyang, W. IL-22 bridges the lymphotoxin pathway with the maintenance of colonic lymphoid structures during infection with Citrobacter rodentium. Nat. Immunol. 2011, 12, 941-948. [CrossRef] [PubMed]

44. Manoharan, I.; Suryawanshi, A.; Hong, Y.; Ranganathan, P.; Shanmugam, A.; Ahmad, S.; Swafford, D.; Manicassamy, B.; Ramesh, G.; Koni, P.A.; et al. Homeostatic PPARalpha Signaling Limits Inflammatory Responses to Commensal Microbiota in the Intestine. J. Immunol. 2016, 196, 4739-4749. [CrossRef] [PubMed]

45. Longstreth, G.F.; Thompson, W.G.; Chey, W.D.; Houghton, L.A.; Mearin, F.; Spiller, R.C. Functional bowel disorders. Gastroenterology 2006, 130, 1480-1491. [CrossRef] [PubMed]

46. Saulnier, D.M.; Riehle, K.; Mistretta, T.A.; Diaz, M.A.; Mandal, D.; Raza, S.; Weidler, E.M.; Qin, X.; Coarfa, C.; Milosavljevic, A.; et al. Gastrointestinal microbiome signatures of pediatric patients with irritable bowel syndrome. Gastroenterology 2011, 141, 1782-1791. [CrossRef] [PubMed]

47. Rajilic-Stojanovic, M.; Biagi, E.; Heilig, H.G.; Kajander, K.; Kekkonen, R.A.; Tims, S.; de Vos, W.M. Global and deep molecular analysis of microbiota signatures in fecal samples from patients with irritable bowel syndrome. Gastroenterology 2011, 141, 1792-1801. [CrossRef]

48. Nomura, T.; Ohkusa, T.; Okayasu, I.; Yoshida, T.; Sakamoto, M.; Hayashi, H.; Benno, Y.; Hirai, S.; Hojo, M.; Kobayashi, O.; et al. Mucosa-associated bacteria in ulcerative colitis before and after antibiotic combination therapy. Aliment. Pharmacol. Ther. 2005, 21, 1017-1027. [CrossRef]

49. Malinen, E.; Krogius-Kurikka, L.; Lyra, A.; Nikkila, J.; Jaaskelainen, A.; Rinttila, T.; Vilpponen-Salmela, T.; von Wright, A.J.; Palva, A. Association of symptoms with gastrointestinal microbiota in irritable bowel syndrome. World J. Gastroenterol. 2010, 16, 4532-4540. [CrossRef]

50. Belmonte, L.; Beutheu Youmba, S.; Bertiaux-Vandaele, N.; Antonietti, M.; Lecleire, S.; Zalar, A.; Gourcerol, G.; Leroi, A.M.; Dechelotte, P.; Coeffier, M.; et al. Role of toll like receptors in irritable bowel syndrome: Differential mucosal immune activation according to the disease subtype. PLOS ONE 2012, 7, e42777. [CrossRef]

51. Chen, Q.; Ren, Y.; Lu, J.; Bartlett, M.; Chen, L.; Zhang, Y.; Guo, X.; Liu, C. A Novel Prebiotic Blend Product Prevents Irritable Bowel Syndrome in Mice by Improving Gut Microbiota and Modulating Immune Response. Nutrients 2017, 9, 1341. [CrossRef]

52. Sun, Y.; Zhang, M.; Chen, C.C.; Gillilland, M.; Sun, X.; El-Zaatari, M.; Huffnagle, G.B.; Young, V.B.; Zhang, J.; Hong, S.C.; et al. Stress-induced corticotropin-releasing hormone-mediated NLRP6 inflammasome inhibition and transmissible enteritis in mice. Gastroenterology 2013, 144, 1478-1487. [CrossRef] [PubMed]

53. Selwyn, F.P.; Cheng, S.L.; Klaassen, C.D.; Cui, J.Y. Regulation of Hepatic Drug-Metabolizing Enzymes in Germ-Free Mice by Conventionalization and Probiotics. Drug Metab. Dispos. Biol. Fate Chem. 2016, 44, 262-274. [CrossRef] [PubMed]

54. Mardini, H.E.; Grigorian, A.Y. Probiotic mix VSL\#3 is effective adjunctive therapy for mild to moderately active ulcerative colitis: A meta-analysis. Inflamm. Bowel Dis. 2014, 20, 1562-1567. [PubMed]

55. Zenhom, M.; Hyder, A.; de Vrese, M.; Heller, K.J.; Roeder, T.; Schrezenmeir, J. Prebiotic oligosaccharides reduce proinflammatory cytokines in intestinal Caco-2 cells via activation of PPARgamma and peptidoglycan recognition protein 3. J. Nutr. 2011, 141, 971-977. [CrossRef] [PubMed]

56. Bomba, A.; Nemcova, R.; Gancarcikova, S.; Herich, R.; Guba, P.; Mudronova, D. Improvement of the probiotic effect of micro-organisms by their combination with maltodextrins, fructo-oligosaccharides and polyunsaturated fatty acids. Br. J. Nutr. 2002, 88, S95-S99. [CrossRef] [PubMed]

57. Lindsay, J.O.; Whelan, K.; Stagg, A.J.; Gobin, P.; Al-Hassi, H.O.; Rayment, N.; Kamm, M.A.; Knight, S.C.; Forbes, A. Clinical, microbiological, and immunological effects of fructo-oligosaccharide in patients with Crohn's disease. Gut 2006, 55, 348-355. [CrossRef] [PubMed]

58. Dziarski, R. Peptidoglycan recognition proteins (PGRPs). Mol. Immunol. 2004, 40, 877-886. [CrossRef] [PubMed]

59. Zenhom, M.; Hyder, A.; Kraus-Stojanowic, I.; Auinger, A.; Roeder, T.; Schrezenmeir, J. PPARgammadependent peptidoglycan recognition protein 3 (PGlyRP3) expression regulates proinflammatory cytokines by microbial and dietary fatty acids. Immunobiology 2011, 216, 715-724. [CrossRef]

60. Peyrin-Biroulet, L.; Beisner, J.; Wang, G.; Nuding, S.; Oommen, S.T.; Kelly, D.; Parmentier-Decrucq, E.; Dessein, R.; Merour, E.; Chavatte, P.; et al. Peroxisome proliferator-activated receptor gamma activation is required for maintenance of innate antimicrobial immunity in the colon. Proc. Natl. Acad. Sci. USA 2010, 107, 8772-8777. [CrossRef] [PubMed] 
61. Mir, S.A.; Nagy-Szakal, D.; Dowd, S.E.; Szigeti, R.G.; Smith, C.W.; Kellermayer, R. Prenatal methyl-donor supplementation augments colitis in young adult mice. PLoS ONE 2013, 8, e73162. [CrossRef] [PubMed]

62. Frolova, L.; Drastich, P.; Rossmann, P.; Klimesova, K.; Tlaskalova-Hogenova, H. Expression of Toll-like receptor 2 (TLR2), TLR4, and CD14 in biopsy samples of patients with inflammatory bowel diseases: Upregulated expression of TLR2 in terminal ileum of patients with ulcerative colitis. J. Histochem. Cytochem. Off. J. Histochem. Soc. 2008, 56, 267-274. [CrossRef] [PubMed]

63. Rakoff-Nahoum, S.; Paglino, J.; Eslami-Varzaneh, F.; Edberg, S.; Medzhitov, R. Recognition of commensal microflora by toll-like receptors is required for intestinal homeostasis. Cell 2004, 118, 229-241. [CrossRef] [PubMed]

64. Lehrke, M.; Lazar, M.A. The many faces of PPARgamma. Cell 2005, 123, 993-999. [CrossRef]

65. Hasan, A.U.; Ohmori, K.; Hashimoto, T.; Kamitori, K.; Yamaguchi, F.; Rahman, A.; Tokuda, M.; Kobori, H. PPARgamma activation mitigates glucocorticoid receptor-induced excessive lipolysis in adipocytes via homeostatic crosstalk. J. Cell. Biochem. 2018, 119, 4627-4635. [CrossRef] [PubMed]

66. Hasan, A.U.; Ohmori, K.; Hashimoto, T.; Kamitori, K.; Yamaguchi, F.; Ishihara, Y.; Ishihara, N.; Noma, T.; Tokuda, M.; Kohno, M. Valsartan ameliorates the constitutive adipokine expression pattern in mature adipocytes: A role for inverse agonism of the angiotensin II type 1 receptor in obesity. Hypertens. Res. 2014, 37, 621-628. [CrossRef] [PubMed]

67. Konner, A.C.; Bruning, J.C. Toll-like receptors: Linking inflammation to metabolism. Trends Endocrinol. Metab. 2011, 22, 16-23. [CrossRef]

68. Turnbaugh, P.J.; Ley, R.E.; Mahowald, M.A.; Magrini, V.; Mardis, E.R.; Gordon, J.I. An obesity-associated gut microbiome with increased capacity for energy harvest. Nature 2006, 444, 1027-1031. [CrossRef] [PubMed]

69. Qin, J.; Li, Y.; Cai, Z.; Li, S.; Zhu, J.; Zhang, F.; Liang, S.; Zhang, W.; Guan, Y.; Shen, D.; et al. A metagenome-wide association study of gut microbiota in type 2 diabetes. Nature 2012, 490, 55-60. [CrossRef] [PubMed]

70. Velloso, L.A.; Folli, F.; Saad, M.J. TLR4 at the Crossroads of Nutrients, Gut Microbiota, and Metabolic Inflammation. Endocr. Rev. 2015, 36, 245-271. [CrossRef] [PubMed]

71. Semova, I.; Carten, J.D.; Stombaugh, J.; Mackey, L.C.; Knight, R.; Farber, S.A.; Rawls, J.F. Microbiota regulate intestinal absorption and metabolism of fatty acids in the zebrafish. Cell Host Microbe 2012, 12, 277-288. [CrossRef]

72. Li, M.; Gu, D.; Xu, N.; Lei, F.; Du, L.; Zhang, Y.; Xie, W. Gut carbohydrate metabolism instead of fat metabolism regulated by gut microbes mediates high-fat diet-induced obesity. Benef. Microbes 2014, 5, 335-344. [CrossRef]

73. Xu, P.; Hong, F.; Wang, J.; Zhao, X.; Wang, S.; Xue, T.; Xu, J.; Zheng, X.; Zhai, Y. DBZ is a putative PPARgamma agonist that prevents high fat diet-induced obesity, insulin resistance and gut dysbiosis. Biochim. Biophys. Acta 2017, 1861, 2690-2701. [CrossRef] [PubMed]

74. Hasan, A.U.; Ohmori, K.; Konishi, K.; Igarashi, J.; Hashimoto, T.; Kamitori, K.; Yamaguchi, F.; Tsukamoto, I.; Uyama, T.; Ishihara, Y.; et al. Eicosapentaenoic acid upregulates VEGF-A through both GPR120 and PPAR $\gamma$ mediated pathways in 3T3-L1 adipocytes. Mol. Cell. Endocrinol. 2015, 406, 10-18. [CrossRef] [PubMed]

75. Cotillard, A.; Kennedy, S.P.; Kong, L.C.; Prifti, E.; Pons, N.; Le Chatelier, E.; Almeida, M.; Quinquis, B.; Levenez, F.; Galleron, N.; et al. Dietary intervention impact on gut microbial gene richness. Nature 2013, 500, 585-588. [CrossRef] [PubMed]

76. Le Chatelier, E.; Nielsen, T.; Qin, J.; Prifti, E.; Hildebrand, F.; Falony, G.; Almeida, M.; Arumugam, M.; Batto, J.M.; Kennedy, S.; et al. Richness of human gut microbiome correlates with metabolic markers. Nature 2013, 500, 541-546. [CrossRef]

77. Ishaq, S.; Nunn, L. Helicobacter pylori and gastric cancer: A state of the art review. Gastroenterol. Hepatol. Bed Bench 2015, 8, S6-s14.

78. Ghose, C.; Perez-Perez, G.I.; van Doorn, L.J.; Dominguez-Bello, M.G.; Blaser, M.J. High frequency of gastric colonization with multiple Helicobacter pylori strains in Venezuelan subjects. J. Clin. Microbiol. 2005, 43, 2635-2641. [CrossRef]

79. Bassaganya-Riera, J.; Dominguez-Bello, M.G.; Kronsteiner, B.; Carbo, A.; Lu, P.; Viladomiu, M.; Pedragosa, M.; Zhang, X.; Sobral, B.W.; Mane, S.P.; et al. Helicobacter pylori colonization ameliorates glucose homeostasis in mice through a PPAR gamma-dependent mechanism. PLoS ONE 2012, 7, e50069. [CrossRef] 
80. Lu, P.; Sodhi, C.P.; Yamaguchi, Y.; Jia, H.; Prindle, T.; Fulton, W.B.; Vikram, A.; Bibby, K.J.; Morowitz, M.J.; Hackam, D.J. Intestinal epithelial Toll-like receptor 4 prevents metabolic syndrome by regulating interactions between microbes and intestinal epithelial cells in mice. Mucosal Immunol. 2018, 11, 727-740. [CrossRef]

81. Lefterova, M.I.; Zhang, Y.; Steger, D.J.; Schupp, M.; Schug, J.; Cristancho, A.; Feng, D.; Zhuo, D.; Stoeckert, C.J.; Liu, X.S.; et al. PPARgamma and C/EBP factors orchestrate adipocyte biology via adjacent binding on a genome-wide scale. Genes Dev. 2008, 22, 2941-2952. [CrossRef]

82. Chalasani, N.; Younossi, Z.; Lavine, J.E.; Charlton, M.; Cusi, K.; Rinella, M.; Harrison, S.A.; Brunt, E.M.; Sanyal, A.J. The diagnosis and management of nonalcoholic fatty liver disease: Practice guidance from the American Association for the Study of Liver Diseases. Hepatology 2018, 67, 328-357. [CrossRef] [PubMed]

83. Gaggini, M.; Morelli, M.; Buzzigoli, E.; DeFronzo, R.A.; Bugianesi, E.; Gastaldelli, A. Non-alcoholic fatty liver disease (NAFLD) and its connection with insulin resistance, dyslipidemia, atherosclerosis and coronary heart disease. Nutrients 2013, 5, 1544-1560. [CrossRef] [PubMed]

84. Duseja, A.; Chawla, Y.K. Obesity and NAFLD: The role of bacteria and microbiota. Clin. Liver Dis. 2014, 18, 59-71. [CrossRef] [PubMed]

85. Donnelly, K.L.; Smith, C.I.; Schwarzenberg, S.J.; Jessurun, J.; Boldt, M.D.; Parks, E.J. Sources of fatty acids stored in liver and secreted via lipoproteins in patients with nonalcoholic fatty liver disease. J. Clin. Investig. 2005, 115, 1343-1351. [CrossRef] [PubMed]

86. Friedman, S.L.; Neuschwander-Tetri, B.A.; Rinella, M.; Sanyal, A.J. Mechanisms of NAFLD development and therapeutic strategies. Nat. Med. 2018, 24, 908-922. [CrossRef] [PubMed]

87. Mardinoglu, A.; Wu, H.; Bjornson, E.; Zhang, C.; Hakkarainen, A.; Rasanen, S.M.; Lee, S.; Mancina, R.M.; Bergentall, M.; Pietilainen, K.H.; et al. An Integrated Understanding of the Rapid Metabolic Benefits of a Carbohydrate-Restricted Diet on Hepatic Steatosis in Humans. Cell Metab. 2018, 27, 559-571. [CrossRef]

88. LeBlanc, J.G.; Laino, J.E.; del Valle, M.J.; Vannini, V.; van Sinderen, D.; Taranto, M.P.; de Valdez, G.F.; de Giori, G.S.; Sesma, F. B-group vitamin production by lactic acid bacteria-current knowledge and potential applications. J. Appl. Microbiol. 2011, 111, 1297-1309. [CrossRef] [PubMed]

89. Pierantonelli, I.; Rychlicki, C.; Agostinelli, L.; Giordano, D.M.; Gaggini, M.; Fraumene, C.; Saponaro, C.; Manghina, V.; Sartini, L.; Mingarelli, E.; et al. Lack of NLRP3-inflammasome leads to gut-liver axis derangement, gut dysbiosis and a worsened phenotype in a mouse model of NAFLD. Sci. Rep. 2017, 7, 12200. [CrossRef]

90. Mei, L.; Tang, Y.; Li, M.; Yang, P.; Liu, Z.; Yuan, J.; Zheng, P. Co-Administration of Cholesterol-Lowering Probiotics and Anthraquinone from Cassia obtusifolia L. Ameliorate Non-Alcoholic Fatty Liver. PLoS ONE 2015, 10, e0138078. [CrossRef]

91. Tomas, J.; Mulet, C.; Saffarian, A.; Cavin, J.B.; Ducroc, R.; Regnault, B.; Kun Tan, C.; Duszka, K.; Burcelin, R.; Wahli, W.; et al. High-fat diet modifies the PPAR-gamma pathway leading to disruption of microbial and physiological ecosystem in murine small intestine. Proc. Natl. Acad. Sci. USA 2016, 113, E5934-E5943. [CrossRef]

92. Cani, P.D.; Bibiloni, R.; Knauf, C.; Waget, A.; Neyrinck, A.M.; Delzenne, N.M.; Burcelin, R. Changes in gut microbiota control metabolic endotoxemia-induced inflammation in high-fat diet-induced obesity and diabetes in mice. Diabetes 2008, 57, 1470-1481. [CrossRef] [PubMed]

93. Wagnerberger, S.; Spruss, A.; Kanuri, G.; Stahl, C.; Schroder, M.; Vetter, W.; Bischoff, S.C.; Bergheim, I. Lactobacillus casei Shirota protects from fructose-induced liver steatosis: A mouse model. J. Nutr. Biochem. 2013, 24, 531-538. [CrossRef] [PubMed]

94. Hsieh, F.C.; Lee, C.L.; Chai, C.Y.; Chen, W.T.; Lu, Y.C.; Wu, C.S. Oral administration of Lactobacillus reuteri GMNL-263 improves insulin resistance and ameliorates hepatic steatosis in high fructose-fed rats. Nutr. Metab. 2013, 10, 35. [CrossRef]

95. Alves, C.C.; Waitzberg, D.L.; de Andrade, L.S.; Dos Santos Aguiar, L.; Reis, M.B.; Guanabara, C.C.; Junior, O.A.; Ribeiro, D.A.; Sala, P. Prebiotic and Synbiotic Modifications of Beta Oxidation and Lipogenic Gene Expression after Experimental Hypercholesterolemia in Rat Liver. Front. Microbiol. 2017, 8, 2010. [CrossRef] [PubMed]

96. Sohn, W.; Jun, D.W.; Lee, K.N.; Lee, H.L.; Lee, O.Y.; Choi, H.S.; Yoon, B.C. Lactobacillus paracasei Induces M2-Dominant Kupffer Cell Polarization in a Mouse Model of Nonalcoholic Steatohepatitis. Dig. Dis. Sci. 2015, 60, 3340-3350. [CrossRef] [PubMed] 
97. Murray, P.J.; Wynn, T.A. Protective and pathogenic functions of macrophage subsets. Nat. Rev. Immunol. 2011, 11, 723-737. [CrossRef] [PubMed]

98. Baffy, G. Kupffer cells in non-alcoholic fatty liver disease: The emerging view. J. Hepatol. 2009, 51, $212-223$. [CrossRef]

99. Wang, Y.; Xie, J.; Li, Y.; Dong, S.; Liu, H.; Chen, J.; Zhao, S.; Zhang, Y.; Zhang, H. Probiotic Lactobacillus casei Zhang reduces pro-inflammatory cytokine production and hepatic inflammation in a rat model of acute liver failure. Eur. J. Nutr. 2016, 55, 821-831. [CrossRef]

100. Chiu, C.C.; Ching, Y.H.; Li, Y.P.; Liu, J.Y.; Huang, Y.T.; Huang, Y.W.; Yang, S.S.; Huang, W.C.; Chuang, H.L. Nonalcoholic Fatty Liver Disease Is Exacerbated in High-Fat Diet-Fed Gnotobiotic Mice by Colonization with the Gut Microbiota from Patients with Nonalcoholic Steatohepatitis. Nutrients 2017, 9, 1220. [CrossRef]

101. Million, M.; Raoult, D. Species and strain specificity of Lactobacillus probiotics effect on weight regulation. Microb. Pathog. 2013, 55, 52-54. [CrossRef]

102. Million, M.; Angelakis, E.; Paul, M.; Armougom, F.; Leibovici, L.; Raoult, D. Comparative meta-analysis of the effect of Lactobacillus species on weight gain in humans and animals. Microb. Pathogen. 2012, 53, 100-108. [CrossRef] [PubMed]

103. Mencarelli, A.; Cipriani, S.; Renga, B.; Bruno, A.; D'Amore, C.; Distrutti, E.; Fiorucci, S. VSL\#3 resets insulin signaling and protects against NASH and atherosclerosis in a model of genetic dyslipidemia and intestinal inflammation. PLoS ONE 2012, 7, e45425.

104. Crawford, P.A.; Crowley, J.R.; Sambandam, N.; Muegge, B.D.; Costello, E.K.; Hamady, M.; Knight, R.; Gordon, J.I. Regulation of myocardial ketone body metabolism by the gut microbiota during nutrient deprivation. Proc. Natl. Acad. Sci. USA 2009, 106, 11276-11281. [CrossRef] [PubMed]

105. Puchalska, P.; Crawford, P.A. Multi-dimensional Roles of Ketone Bodies in Fuel Metabolism, Signaling, and Therapeutics. Cell Metab. 2017, 25, 262-284. [CrossRef] [PubMed]

106. Rastaldo, R.; Pagliaro, P.; Cappello, S.; Penna, C.; Mancardi, D.; Westerhof, N.; Losano, G. Nitric oxide and cardiac function. Life Sci. 2007, 81, 779-793. [CrossRef] [PubMed]

107. Massion, P.B.; Feron, O.; Dessy, C.; Balligand, J.-L. Nitric Oxide and Cardiac Function: Ten Years After, and Continuing. Circ. Res. 2003, 93, 388-398. [CrossRef]

108. Maccallini, C.; Mollica, A.; Amoroso, R. The Positive Regulation of eNOS Signaling by PPAR Agonists in Cardiovascular Diseases. Am. J. Cardiovasc. Drugs Drugs Devices Other Interv. 2017, 17, 273-281. [CrossRef]

109. Wang, Z.; Klipfell, E.; Bennett, B.J.; Koeth, R.; Levison, B.S.; DuGar, B.; Feldstein, A.E.; Britt, E.B.; Fu, X.; Chung, Y.-M.; et al. Gut flora metabolism of phosphatidylcholine promotes cardiovascular disease. Nature 2011, 472, 57-63. [CrossRef]

(C) 2019 by the authors. Licensee MDPI, Basel, Switzerland. This article is an open access article distributed under the terms and conditions of the Creative Commons Attribution (CC BY) license (http:/ / creativecommons.org/licenses/by/4.0/). 